Harvard Data Science Review • Issue 2.1, Winter 2020

\title{
Oscar Seasons: The \\ Intersection of Data and \\ the Academy Awards
}

\section{Ben Zauzmer ${ }^{1}$}

${ }^{1}$ Freelance Reporter

Published on: Jan 31, 2020

DOI: https://doi.org/10.1162/99608f92.6230ce9f

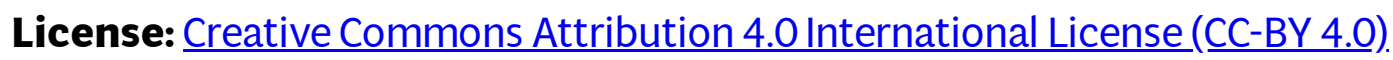


Column Editor's Note: For the inaugural article of Recreations in Randomness, Ben Zauzmer, a movie fan and noted 'Oscarmetrician,' explains how movies with the greatest chance for success at the Academy Awards tend to be released closer to the date of the awards ceremony. Data science provides some insights into why this may be the case, and, as Ben clarifies, whether other factors are at play.

Keywords: motion pictures, trend, movie release date, box office success

It's the Fourth of July, 2018. It's hot outside, the barbecue doesn't start for a few hours, and the fireworks aren't until later tonight. You'd like to go somewhere with air conditioning and entertainment-how 'bout a movie? If, like me, you're an Oscars fan, maybe you'd like to get a head start on this year's Best Picture nominees.

Trouble is, you can’t. You’ve probably already seen Marvel’s \$1.3 billion (Box Office Mojo, 2019) hit Black Panther - that came out way back on February 16 —and as you'd discover at next year's Oscar nominations announcement, no other Best Picture nominee has been released yet.

At first glance, this is a little surprising. On July 4th, we're already 51\% through the calendar year, but of the eight films that would go on to be nominated for the Academy Awards' highest category, only one of them has already hit theaters. What's more, by the end of September, only one other nominee (Spike Lee's BlacKkKlansman) would be released.

And this isn't just a one-year fluke. The Academy Awards honor the year's best in film, and since 1934 they've considered all motion pictures released in Los Angeles between January 1 and December 31 (Academy of Motion Picture Arts and Sciences, 2019). The median release date of Best Picture nominees is September 4, on a scale from January 1 at one end to December 31 at the other. That's over two months after July 2, the median date of the calendar year. Using data downloaded from the Internet Movie Database, and taking the first release with a specific associated date from the release information page, we can further see this trend by breaking down the number of Best Picture releases by month since 1934 as shown in Figure 1. 


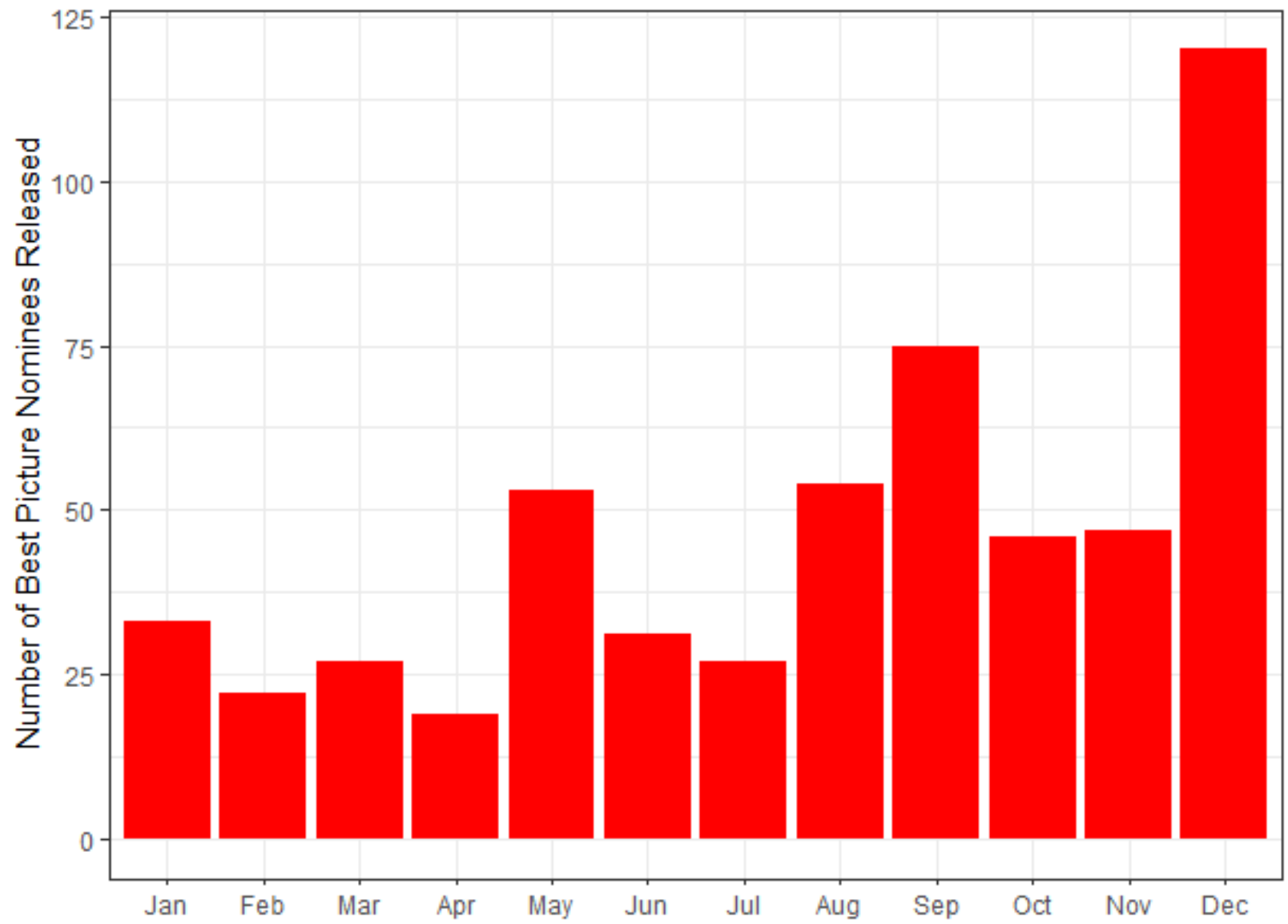

Figure 1. The number of Best Picture nominees released each month since 1934.

The six least frequent months of the year for releasing Best Picture nominees are all between January and July, and no month comes close to the frequency of December releases, just before the cutoff date for Oscar eligibility.

Other studies have confirmed this phenomenon. For example, a recent study by Kram (2018) expanded the sample to include not just Best Picture but also Best Director, Best Actor, and Best Actress. The results pointed to three phases over Oscar history in how release dates related to the award results. Until the 1970s, no discernible pattern was found. From the late 1970s to the mid-2000s, the best time to release Oscar hopefuls was in December. Since then, with earlier dates for the Academy Awards, the optimal time has shifted backwards to October and November.

Much of this push toward later releases is driven by more recent Oscar seasons. The graph in Figure 2 shows the elapsed time between the average date in a given year of Best Picture nominees entering theaters and the day of the Oscar ceremony. The black dots represent individual years, the red curve is a type of moving average of the time duration between the nominees' average premiere date and the Oscar ceremony, and the grey shaded area around the red curve is a confidence band, indicating the degree of trust in the red curve. The purpose of this standard smoother (in red) is to make the trend in the black dots easier to see. 


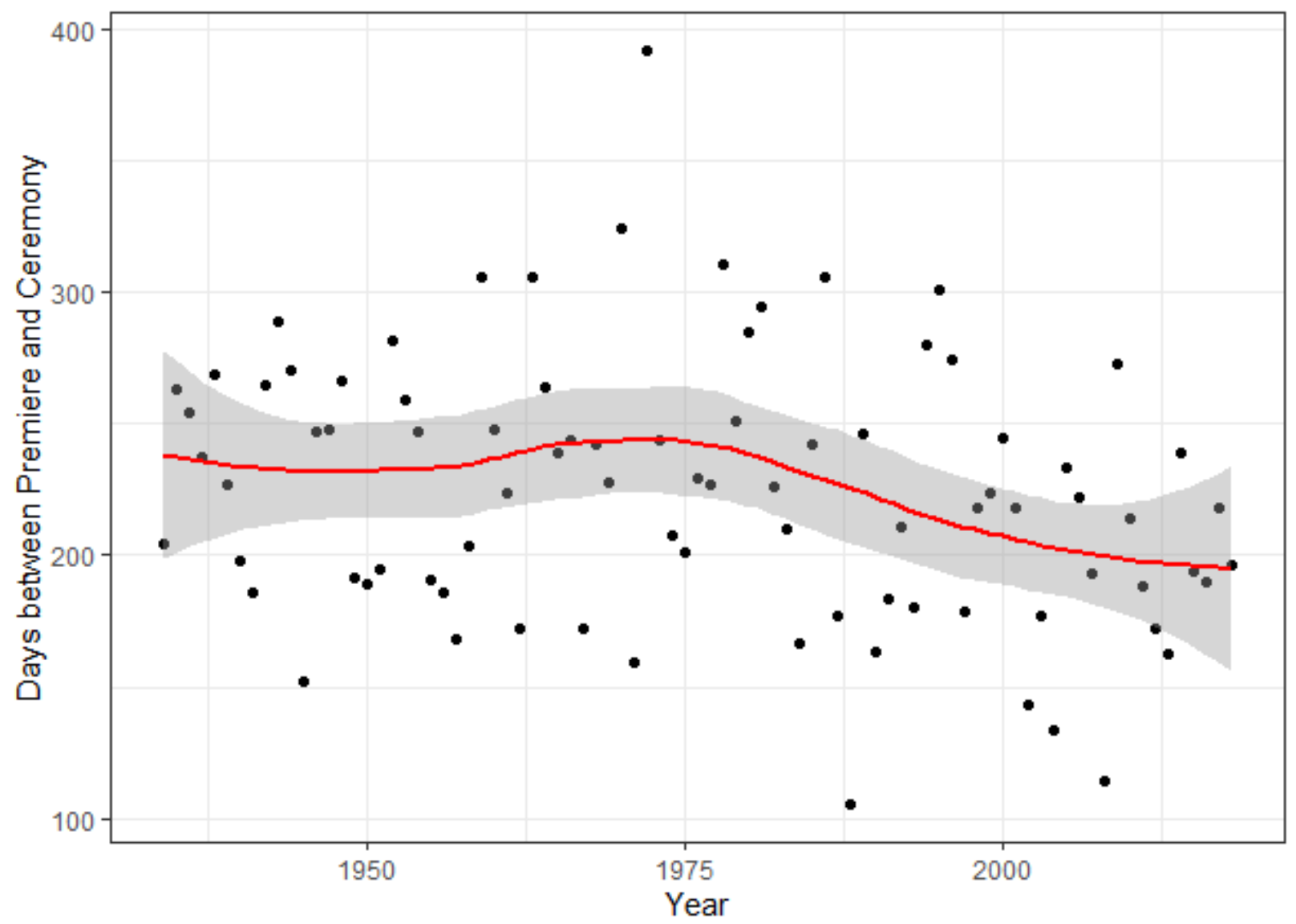

Figure 2. Scatter plot of the average number of days between a movie's premiere date and Oscar ceremony date for all Best Picture nominees within a year.

The red trend curve is a LOESS smoother evaluated at 80 points with a span parameter 0 f 0.75 , and the grey band shows pointwise 95\% confidence intervals.

The curve has clearly been going down since the mid-1970s, indicating less elapsed time between the Oscars and the films they're honoring. The waters are muddied by some years having earlier ceremony dates than others, but part of it is due to contenders coming out later and later in the year.

Are studios wise to be releasing their contenders so late in the year? A number of studies on the subject say the answer is yes, for two reasons. Nelson, Donihue, Waldman, and Wheaton (2001) analyzed release date data, similar to the data displayed in Figures 1 and 2. They concluded that not only does a late release date improve the probability a film is nominated for an Oscar, but that the likely financial rewards associated with a possible Oscar nomination incentivizes a late release.

In other words, later release dates can be wise for a studio with an Oscar-ready movie to release, both to increase the chances of a nomination and of a financial windfall. Surveying other studies on the matter, we can discover whether those proposed explanations are correct. 


\section{Later Release Dates Increase Nomination Probabilities}

The first justification, and perhaps the most natural one to fans of the Academy Awards, is that studios believe that later release dates can help their films be nominated for and win trophies. Voters may be more likely to remember the films that came out more recently, shortly before the voter ballots arrive (Kaplan, 2006), and they may be more inclined to vote for films released in the traditional Oscar season comprising the final three months of the year.

For example, Rossman, Esparza, and Bonacicha (2010) analyzed which factors are most likely to lead to acting nominations. They fit four different models, which included varying amounts of information about the cast, director, and writers, and all four of them reached the conclusion that actors who were in dramatic or biographical genre films released late in the year had a significantly improved probability of being nominated for an Oscar. Their study provided rather clear evidence that later releases do in fact lead to kinder verdicts from academy voters.

However, when it comes to actually winning those awards, another study showed more ambiguity as to the effect of release date. Kaplan (2006) performed a series of analyses in which he examined whether a movie released in the fourth quarter of the year was predictive of winning an Oscar. These analyses concluded that while fourth-quarter release was positively related to Oscar winning, the relationship was not statistically significant. So the jury is still out on how much a late release helps nominees win their awards on Oscar Sunday.

This first explanation suggests that Oscar success and revenue are two different goals, and releasing films geared toward awards on a certain date is primarily concerned with trophies, not riches. There is, however, another explanation that would suggest that the goals of film honors and the studio's bottom line go hand-inhand.

\section{Later Release Dates Add Revenue for Oscar Nominees}

The second justification for studios to release awards contenders later in the year is that those award-worthy films themselves can take advantage of an Oscar boost in revenue. Some fans (including yours truly) see newly announced Oscar nominees in order to check off as many nominees as possible before the awards show begins. Others may be more inclined to see Oscar nominees simply because the nominations announcement serves as a form of advertising, highlighting the film's existence to potential viewers that might not have had the movie on their entertainment radar.

A study by Deuchert. Adjamah, and Pauly (2005) examined how the Academy Awards relate to the box office along a number of different dimensions. The study found strong evidence that nominations in some of the most prominent categories-Best Picture, Best Actor, and Best Actress—-were tied to increased revenue. Specifically, the study found that box office revenue in the following weeks after a nomination of Best Picture 
or Best Actor increased by more than $200 \%$, and that the revenue after a nomination of Best Actress increased by about $150 \%$. A studio need look no further to justify why spending money on that Oscar campaign could be a wise investment, with nominations clearly resulting in improved box office totals.

In a review article, McKenzie (2012) examined previous published work on the subject and came to a similar conclusion. This study noted that distributors make release date decisions to improve the chance a film is nominated for an award. The distributors would then use the nomination or award in marketing the film thereafter. McKenzie's analysis adds the 'why' to the 'what.' The method for translating nominations or awards into revenue is often marketing campaigns, as studios can brag about their recent Academy honors on posters, television spots, and the like in hopes of convincing viewers that their film is worthwhile.

According to this dataset, no July release has ever won Best Picture, making it the worst month to have premiered an Oscar hopeful. The best month is November, with a $27.7 \%$ winning rate. July is often considered to be the apex of popcorn movies, so the Fourth of July anecdote that began this piece made for a particularly unlikely date to see the year's Best Picture champion.

There are, of course, exceptions to every rule. Western film Cimarron (1931), British drama Cavalcade (1933), circus tale The Greatest Show on Earth (1952), and horror classic The Silence of the Lambs (1991) all won Best Picture despite January openings. In fact, each of the last five years has had at least one nominee with a January premiere (in some cases, the films did not reach a wider audience until later in the year), though none of those early birds went on to get the Best Picture worm over a year later.

And just because there is some correlation between release date and Oscar results, that does not mean that premiere month is the strongest predictor of the Academy Awards. Krauss, Nann, Simon, Fischbach, and Gloor (2008), for example, found that once an analysis controlled for other factors, the best Oscar model was one that ignored "time noise factor," their rescaling of release date. Therefore, it’s plausible that the correlation identified at the outset of this article between release date and the Oscars is merely that—correlation—and is insufficient to prove causation.

Pardoe and Simonton (2008) concurred, finding that release date-among other potential factors—did not improve the predictive ability of a model designed to forecast Oscar winners. They build models to predict Best Picture, Best Director, Best Actor, and Best Actress, but none of them were aided by knowledge of the release date after more predictive factors (e.g., number of nominations per film, results at precursor awards shows) had been included.

However, the existing literature is not unanimous on the conclusion that release date does not affect Oscar success. Pathak, Rothschild, and Dudik (2015) came to a more nuanced conclusion, observing that later release dates are correlated with higher likelihoods of receiving Oscar nominations, but that among nominated films, 
the release date did not help predict which of those nominees would win the trophy. So, a later release date can get a movie invited to the prom, but it can’t necessarily promote it to prom king or queen.

A caveat to all of these studies is that there have only been 91 years of the Academy Awards, so all of this is dealing in relatively small sample sizes. As the decades go by, film-watching habits change, and individual studios and movies break old molds; perhaps one year we can celebrate Fourth of July by watching the Best Picture of the year.

\section{Disclosure Statement}

Ben Zauzmer has no financial or non-financial disclosures to share for this article.

\section{References}

Academy of Motion Picture Arts and Sciences. (2019). 92nd Academy Awards of Merit. Retrieved from https://www.oscars.org/sites/oscars/files/92aa rules.pdf

Alonso, V., Chernov, J., D'Esposito, L., Feige, K., Lee, S., Moore, N. (Producers), \& Coogler, R. (Director). (2018). Black panther [Motion Picture]. United States: Marvel Studios, Walt Disney Pictures.

Blum, J., Brown, M., Cherry, M., Hamm, E., Lee, S., Mansfield, R., McKittrick, S., Peele, J., Redick, S., Rosenfeld, W., Volturno, J. (Producers), \& Lee, S. (Director). (2018). BlacKkKlansman [Motion Picture]. United States: Focus Features, Legendary Entertainment, Perfect World Pictures.

Box Office Mojo. (2019). Black panther. Retrieved from https://www.boxofficemojo.com/movies/? $\underline{\mathrm{id}=\text { marvel2017b.htm }}$

Bozman, R., Goetzman, G., Saxon, E., Utt, K. (Producers), \& Demme, J. (Director). (1991). The silence of the lambs [Motion Picture]. United States: Strong Heart/Demme Production, Orion Pictures.

DeMille, C. (Producer), \& DeMille, C. (Director). (1952). The greatest show on Earth [Motion Picture]. United States: Paramount Pictures.

Deuchert, E., Adjamah, K., \& Pauly, F. (2005). For Oscar glory or Oscar money? Academy Awards and movie success. Journal of Cultural Economics, 29(3), 159-176. https://doi.org/10.1007/s10824-005-3338-6

Frank Lloyd, F., Sheehan, W. (Producers), \& Lloyd, F. (Director). (1933). Cavalcade [Motion Picture]. United States: Fox Film Corporation.

Kaplan, D. (2006). And the Oscar goes to... a logistic regression model for predicting Academy Award results. Journal of Applied Economics \& Policy, 25(1), 23-41. 
Kram, Z. (2018, February 28). Can a release date predict an Oscar winner? The Ringer. Retrieved from https://www.theringer.com/oscars/2018/2/28/17060396/best-oscar-movie-release-date

Krauss, J., Nann, S., Simon, D., Fischbach, K., \& Gloor, P. (2008). Predicting movie success and Academy Awards through sentiment and social network analysis. Paper presented at the 16th European Conference on Information Systems. https://aisel.aisnet.org/ecis2008/116

LeBaron, W., Ruggles, W. (Producers), \& Ruggles, W. (Director). (1931). Cimarron [Motion Picture]. United States: RKO Radio Pictures.

McKenzie, J. (2012). The economics of movies: A literature survey. Journal of Economic Surveys, 26(1), 4270. https://doi.org/10.1111/j.1467-6419.2010.00626.x

Nelson, R., Donihue, M., Waldman, D., \& Wheaton, C. (2001). What's an Oscar worth? Economic Inquiry, 39(1), 1-6. https://doi.org/10.1111/j.1465-7295.2001.tb00046.X

Pardoe, I., \& Simonton, D. K. (2008). Applying discrete choice models to predict Academy Award winners. Journal of the Royal Statistical Society: Series A, 171(2), 375-394. https://doi.org/10.1111/j.1467$\underline{\text { 985X.2007.00518.X }}$

Pathak, D., Rothschild, D., \& Dudik, M. (2015). A comparison of forecasting methods: Fundamentals, polling, prediction markets, and experts. The Journal of Prediction Markets, 9(2), 1-31. https://doi.org/10.5750/jpm.v9i2.1048

Rossman, G., Esparza, N., \& Bonacicha, P. (2010). I'd like to thank the Academy, team spillovers, and network centrality. American Sociological Review, 75(1), 31-51. https://doi.org/10.1177/0003122409359164

(C2020 Ben Zauzmer. This article is licensed under a Creative Commons Attribution (CC BY 4.0) International license, except where otherwise indicated with respect to particular material included in the article. 